\title{
A CONSTITUIÇÃO DO REINO DA SUÉCIA, O ESTADO-PROVIDÊNCIA E O ESTADO MÍNIMO
}

THE CONSTITUTION OF THE KINGDOM OF SWEDEN, WELFARE STATE AND MINIMAL STATE 1

Ricardo Antonio Lucas Camargo ${ }^{1}$

Resumo: $O$ presente ensaio volta-se, diante do recorrente discurso de minimização do Estado como o verdadeiro caminho para o bem-estar geral, a examinar a veracidade das proposições que têm sido frequentes em relação ao Reino da Suécia, particularmente no que tange ao modo de gestão da res publica e à passagem de um modelo econômico de Estado Providência para o de um Estado Mínimo. A verificação dessas premissas foi realizada pelo estudo da formação da Suécia enquanto Estado, bem como da distribuição dos poderes no âmbito deste, para se ingressar no tratamento dos temas econômicos por parte do ordenamento jurídico, destacados a propriedade, o trabalho, a atividade empresarial, a atuação do Estado em face do domínio econômico e os serviços públicos. Uma vez que o artigo se constrói pelo teste das proposições gerais, impõe-se a adoção do método indutivo.

Palavras-chave: Constituição Econômica. Suécia. Estado Providência.

\begin{abstract}
This essay intends, facing the continuous speech on reducing the State as the real way to the general welfare, to investigate the truth on propositions related to the Kingdom of Sweden, specially on what concerns the way of managing res publica and the transition from an economic model of a Welfare State to a Minimal State. These premises verification were made through the formation of Sweden as a State, as well as the distribution of powers inside it, in order to come into legal treatment of economic themes, with emphasis on property, work, business activity, State action in economic field and public utilities. Inductive method is, here, imperative, for this essay is built by testing general propositions.
\end{abstract}

Keywords: Economic Constitution. Sweden. Welfare State.

\footnotetext{
1 Doutor e Graduado em Direito pela Universidade Federal de Minas Gerais; Professor permanente do Curso de Pós-Graduação na Faculdade de Direito da Universidade Federal do Rio Grande do Sul; Avenida Paulo Gama, 110, Farroupilha, 90040-060, Porto Alegre, Rio Grande do Sul, Brasil; ricardocamargo3@hotmail.com
} 


\section{Introdução}

A queda do Muro de Berlim, como se sabe, deu um grande alento aos adversários do denominado "Estado-Providência" para construírem o discurso no sentido de que a redução do Estado ao mínimo seria a grande receita para que o verdadeiro bem-estar social se viesse a implementar, arredando a corrupção e moralizando os costumes como um todo.

O Reino da Suécia é visto como o modelo em que o "Estado-Providência" assumiu a feição mais sofisticada, e tem sido objeto de interesse, também, por parte da opinião pública brasileira, em termos de seriedade no trato com a coisa pública.

Ainda, chamou-se a atenção para o fato de que o Reino da Suécia teria procedido a uma liberalização do Estado, dando a entender que teria, praticamente, passado de um modelo de Estado Providência para o Estado Mínimo.

Diante de tantas preocupações trazidas pelo senso comum, cabe ao cientista do Direito convertê-las em problemas, isto é, convertê-las em perguntas a serem respondidas a partir do exame dos dados de fato pertinentes e do direito positivo vigente naquele País.

Procurar-se-á expor a configuração político-constitucional da Suécia, mediante rápido bosquejo sobre a sua formação como Estado Nacional e a retomada do conceito de Constituição Econômica, para se identificar a respectiva localização formal.

Em seguida, entre as matérias recorrentes na análise do tema, serão examinados aspectos dos regimes jurídicos da propriedade, do trabalho e da atividade empresarial, da atuação estatal em relação ao domínio econômico e dos serviços públicos.

Tanto quanto possível, serão utilizadas fontes doutrinárias daquele País, quando estiverem em idiomas mais acessíveis à maior parte da população mundial, e será realizada a comparação com o posicionamento, sobretudo legislativo e doutrinário, brasileiro a respeito dos mesmos temas.

Como serão examinados dados particularizados para o teste de proposições gerais, o método adotado será o "indutivo", embora alguns conceitos gerais venham a ser reavivados para operacionalizarem a compreensão dos temas jurídicos que se fazem presentes neste texto.

\section{Da configuração político-constitucional da Suécia e da respectiva constituição econômica}

O exame da veracidade das proposições relacionadas ao caráter do Reino da Suécia demanda, antes de mais nada, a verificação da respectiva formação como Estado e de como se põe a distribuição dos poderes no âmbito deste mesmo Estado.

Dos suecos já se tem notícia no Ocidente, pelo menos, desde a Antiguidade, embora as suas incursões pela Europa, tanto pelas costas do Atlântico quanto pelas do Báltico, tenham sido 
mais intensas durante a Alta Idade Média, tendo no século XI ali ingressado o cristianismo (MUSSET, 1951, p. 130-131).

É sobejamente conhecido o dado de que um dos principais entraves ao desenvolvimento do mercado durante a Idade Média nos principados europeus foram os encargos financeiros impostos pelos senhores feudais, tendo a Suécia adotado, ao contrário, a unidade aduaneira, incorporando a ela, rapidamente, os territórios conquistados (HECKSCHER, 1983, p. 40, nota 9).

Os Países Nórdicos têm cultura e tradições comuns, lastreadas em valores democráticos e sociais, bem como no Estado de Bem-Estar Social (BERNITZ, 2007b, p. 16), sendo de notar, ainda, que dois deles - a Suécia e a Dinamarca - constituíram-se como Estados Nacionais ainda na Idade Moderna, tendo os demais conquistado a respectiva independência no século XX (SVÅSAND; LINDSTRÖM, 1992, p. 331).

Uma das mais interessantes características do comércio exterior durante a época mercantilista no Estado sueco foi o estabelecimento, por força das Ordenações do Comércio de 1614 e 1617, da distinção entre as cidades de depósito, que eram as únicas autorizadas a serem visitadas por estrangeiros e com estes comerciar, e as cidades interiores, que tinham de recorrer às cidades de depósito não somente para a obtenção das mercadorias provenientes do exterior mas também para propiciarem a remessa das respectivas mercadorias (HECKSCHER, 1983, p. 514-515).

Vale notar, também, a criação, em 1615, do Banco Palmstruch, de Estocolmo, mais tarde convertido em Riksbank, considerado o primeiro exemplo relevante de Banco de Emissão (WICKSELL, 1947, p. 258-259).

A Suécia já exerceu a soberania sobre o território que hoje se conhece por Finlândia, que foi anexada no século XIII em nome da expansão do cristianismo (MUSSET, 1951, p. 236-238) e dela se separou em 1809 para se tornar um Grão-Ducado sob a tutela russa, e de 1814 a 1905, uniu a sua Coroa à da Noruega (BERNITZ, 2007b, p. 16).

Cabe destacar que desde a Revolução de 1809, que destronou o aliado dos Bourbons, Gustavo IV Wasa, e entronizou Carlos XIII - que, por não ter filhos, adotou como tal e fez seu sucessor o Marechal Jean-Baptiste Bernadotte, que mais tarde seria o Rei Carlos XIV (NABONNE, 1940, p. 192) -, a ideia de monarquia constitucional esteve firme entre os suecos, temerosos dos reis que pudessem amesquinhar, com o exercício de poderes despóticos, as prerrogativas, principalmente, da nobreza, razão por que adveio o Instrumento de Governo daquele ano (BEAUMONT-VASSY, 1841, p. 101; BURDEAU, 1953, p. 65), que vigorou até 1974 (STJERNQUIST, 1962, p. 203).

Antes de prosseguir, cabe retomar o conceito de Constituição Econômica, enquanto o conjunto de princípios e normas que configurarão uma determinada ordem econômica, tanto na condição de uma garantia jurídica da forma de um determinado sistema econômico quanto de um fundamento de determinada ordem econômica (MOREIRA, 1974, p. 39; SOUZA, 2002b, p. 38-39).

Este conceito não implica a adoção do entendimento da distinção da Constituição Econômica em face do todo do sistema constitucional, mas apenas a identificação de um segmento, que se 
compõe das normas de conteúdo econômico tomadas em consideração no Texto Fundamental e que deverá ser tomado em harmonia com todo o restante desse mesmo Texto (HORTA, 2010, p. 235).

Atualmente, a Constituição Econômica do Reino da Suécia pode ser localizada no Instrumento de Governo, de 1975 (SWEDEN, 2016), ${ }^{2}$ que, no artigo $3^{\circ}$ de seu capítulo 1, reconhece, ao seu lado, documentos constitucionais anteriores, como a Lei de Sucessão de 1810, a Lei de Liberdade de Imprensa e a Lei Fundamental de Liberdade de Expressão.

A técnica legislativa do Instrumento de Governo de 1975 aproxima-se da adotada na maior parte dos países de Direito Codificado, embora com a peculiaridade de retomar a numeração dos artigos a cada novo capítulo.

Pareceria algo estranhável considerar, além do instrumento de Governo, as Leis de Imprensa e de Liberdade de Expressão como integrantes da Constituição Econômica sueca se já não houvessem sido discutidos os pontos de conflito aparente com uma das mais sensíveis armas empregadas na atividade empresarial, qual seja, o sigilo comercial e de fábrica (VINKA, 1999/2000, p. 36-37), além das questões relacionadas com os condicionamentos da atividade das empresas jornalísticas, fiscalizada pelo Ombudsman da Imprensa e julgada por uma Corte Arbitral, o Conselho da Imprensa, a partir da autorregulação posta pelas entidades de imprensa, rádio e televisão e que versa temas como a verificação das fontes e a correta divulgação das notícias, o respeito à privacidade, os critérios para a disposição das imagens e o direito de resposta (BERNITZ, 2013, p. 35)

O regime de Governo é a monarquia parlamentar, com uma Assembleia (Riksdag) unicameral que trabalha por Comissões, sendo de notar que mesmo repartições, sejam do Executivo - como o Riksbank e a Procuradoria-Geral -, sejam do Legislativo - como a Repartição da Dívida Nacional, as agências de supervisão - guardam certo grau de autonomia, sem comprometimento, entretanto, do comando político (NEUMANN, 1960, p. 698), o que se explica pela clara compreensão das normas de competência como definidoras da legitimação jurídica para a prática válida de determinados atos (STRÖMBERG, 1984, p. 156).

O Executivo, comandado pelo Conselho de Ministros, envia instruções escritas para as denominadas Comissões Reais acerca dos objetivos e problemas a serem resolvidos, às quais incumbe preparar informes para os projetos legislativos (SÁNCHEZ DE DIOS, 1993, p. 289) e responder, enquanto responsável pelo Governo, perante o Riksdag, figurando o Rei como Chefe de Estado (HORTA, 2010, p. 618), ao qual incumbe, além de representar o Reino da Suécia no âmbito internacional, designar o Primeiro Ministro (BURDEAU, 1957, p. 318).

Além das Cortes Judiciárias, tem o Reino da Suécia uma jurisdição administrativa voltada a dirimir os litígios em sede de "Direito Público" (PERLINGEIRO, 2012, p. 7), empregada esta expressão commoditatis causa, considerando que cada vez mais vem sendo posta em discussão a dicotomia (KELSEN, 1974, p. 240; MATA-MACHADO, 1972, p. 167-168).

\footnotetext{
2 A numeração segue esta edição.
} 
Uma das principais inovações do Instrumento de Governo atualmente em vigor é a ênfase dada ao Governo local - entenda-se aqui por autonomia municipal, já que se trata de um Estado unitário - para fins administrativos, como um dos traços caracterizadores do regime sueco como "democrático" (NYMAN, 1982, p. 175).

Vale também destacar que, ali, os trabalhos preparatórios de elaboração legislativa assumem relevância enquanto fontes do Direito (ALHAGER, 2003, p. 15; WALIN, 1956, p. 393), diversamente do que ocorre no Brasil, onde os trabalhos legislativos são tomados em consideração em último lugar (SILVEIRA, 1968, p. 97-98; MAXIMILIANO, 2002, p. 119).

Veja-se, agora, o quanto se pode falar em um compromisso estrito da ordem constitucional sueca com um modelo totalmente fiel ao liberalismo econômico, isto é, em que a propriedade privada e a liberdade de negociar e de explorar atividade econômica estariam postas como pilares do funcionamento da economia, restrito o Estado a algumas poucas manifestações voltadas a viabilizar tal funcionamento.

\section{Propriedade}

Qualquer que seja o pendor ideológico do analista, não restam dúvidas de que a configuração da possibilidade de usar, gozar, dispor e reivindicar de quem ilegitimamente decida exercer qualquer desses direitos sobre os bens constitui traço indispensável à identificação do sistema econômico que se tenha sob exame.

Os temas da propriedade e da liberdade de iniciativa comparecem como elementos próprios da ideologia liberal no Capítulo 2, artigos 15 e 17, tratados como direitos individuais, na crença de que o bem-estar geral seria o fruto impremeditado da perseguição, por cada qual, do bem-estar próprio (SCHMIDT, 1977, p. 253).

A propriedade, ali, distingue-se em "real" - o equivalente, entre nós, a "imóvel" - e "móvel", sendo esta última definida por exclusão pela Lei de Terras (HAMMARSKIÖLD; JANSSON; GRÜBBSTRÖM, 2005, p. 425-426), merecendo destaque o dado de que já se identificaram ali, como seus desdobramentos, a liberdade de disposição e uso, o direito à obtenção de frutos, tanto naturais quanto civis, e a evitar a deterioração da coisa, o direito à compensação de eventuais perdas e a liberdade negocial (SKOGH, 2000, p. 494-495).

A possibilidade de desapropriação ou de ônus equivalentes, compensáveis mediante indenização, determinada nos termos da lei, também comparece, como elemento típico da ideologia liberal, embora não sejam indicados, ao contrário do que ocorre nas Constituições brasileiras, os pressupostos para a desapropriação, no mesmo artigo 15 do Capítulo 2 do Instrumento de Governo.

Entretanto, comparecem como fundamentos para a limitação do uso da terra ou das construções a proteção à saúde humana ou ao meio ambiente ou em prol da segurança, que deverão ser objeto de indenização, com lastro neste mesmo artigo 15 do Capítulo 2. 
Por sua amplitude, essa mesma disposição tem tornado mais difícil a impugnação judicial às restrições econômicas impostas pelo Governo, razão pela qual, com algum exagero - exagero, sim, porque se tem presente o exemplo empregado por um dos clássicos do pensamento sueco para afirmar o caráter não fantasioso do direito subjetivo (OLIVECRONA, 1959, p. 143-144) -, há quem sustente que a propriedade privada, na Suécia, não é tratada como um direito (SÁNCHEZ DE DIOS, 1993, p. 288), embora seja digno de registro que a preocupação com a tutela dos direitos fundamentais, notadamente em sua dimensão individual, veio a reforçar-se por influência do Direito Comunitário (BERNITZ, 2007a, p. 61).

Vale observar que o mesmo dispositivo contém, desde 1999, o direito ao acesso ao meio ambiente natural (PLAUEN, 2005, p. 928; SKOGH, 2000, p. 501), apresentando-se como uma restrição à propriedade individual que vai além da própria atribuição de uma "função social", trazendo dados à reflexão sobre a categoria mais ampla da "apropriação" (MOLL, 1995, p. 148).

Por sinal, recorde-se que um dos grandes eventos relacionados à questão do equilíbrio entre as necessidades da economia e o problema ecológico veio a ocorrer precisamente na capital sueca, em 1972 (BASSE, 2001, p. 32; SAMPAIO, 1991, p. 45; SANTANA, 2004, p. 45).

Embora tenha uma das mais antigas legislações ambientais do mundo, o seguro pela responsabilidade civil ambiental obteve disciplina na Suécia somente em 1986, operacionalizando-se mediante a formação de grupos econômicos e de contratação obrigatória para as empresas que desempenhem atividades tidas como perigosas para o meio ambiente (PORCIONATO; LOBO, 2007, p. 82).

É, por força do artigo 17 do Capítulo 2, que foi reconhecido à população Sami o direito ao pastoreio de renas, a ser disciplinado em lei, admitindo, pois, a presença de uma atividade inerente ao "sistema da tradição" em meio a um típico "sistema econômico da autonomia" (NUSDEO, 2015, p. 100-101; SKOGH, 2000, p. 489).

Note-se, aqui, o reconhecimento, como um direito fundamental, de um traço característico da cultura de um dos segmentos étnicos presentes no Estado sueco, com implicações na dimensão em que garantido o direito de propriedade dos demais submetidos ao ordenamento daquele País no âmbito rural e na própria exploração dos recursos do subsolo, como salientou, em 2011, julgado da Corte Suprema respectiva (INSTITUT SUÉDOIS, 2011; LAPEYRE, 2007; SYMONIDES, 2012), com o que se verifica não somente uma rejeição do viés ideológico "assimilacionista", no plano jurídico-formal - o que, desde logo, aponta para um parentesco ao tratamento dado pelo artigo 231 da Constituição brasileira de 1988 ao tema indígena - como também a permanência de conflitos naquele País cujas razões são aparentadas às que se verificam no Brasil (SOUZA FILHO, 2012, p. 120; LEAL JÚNIOR, 2012, p. 106; MONTEIRO, 2010, p. 29 ; FERREIRA, 2012, p. 20-21; BRITTO, 2010, p. 50-51; VIEIRA, 2008, p. 39-41; GONÇALVES, 2015, p. 62-63; SANTILLI, 1993, p. 159-160).

Ainda, como desdobramento da tutela do direito de propriedade, também como manifestação típica da ideologia liberal, a competência do Parlamento para a instituição e majoração de tributos 
e aprovação do orçamento nacional é assinalada pelo artigo $1^{\circ}$ do Capítulo 9 do Instrumento de Governo, reforçando a reserva estabelecida em caráter geral posta no item 2 do artigo $2^{\circ}$ do Capítulo 8 .

A influência do fato econômico "repartição", já na Lei Tributária de 1910, faz-se presente pela adoção de alíquotas progressivas (ANDERSSON, 1986, p. 16), adotadas também no Brasil, embora, neste, por vezes, se lhes questione a própria finalidade e compatibilidade com o regime da propriedade privada (ÁVILA, 2012, p. 447; TORRES, 2013, p. 66-67; CARRAZZA, 2011, p. 545, nota 21; DIFINI, 2007, p. 156-157; BORGES, 1992, p. 80).

A questão da diversidade de tratamentos tributários conforme o setor de atividade poder configurar ou não agressão à isonomia tem-se posto ali (ALHAGER, 2003, p. 17-8), do mesmo modo que os debates que se travam acerca do inciso II do artigo 150 da Constituição brasileira de 1988 (ÁVILA, 2009, p. 115-116; TORRES, 2013, p. 77-78; CARRAZZA, 2011, p. 99-100).

Os expedientes negociais mercê dos quais se opta, licitamente, pelo que acarrete o menor ônus tributário e, ipso facto, sacrifique o mínimo possível a propriedade do sujeito passivo, e a sua distinção dos expedientes voltados a burlar a tributação têm sido, na Suécia, examinados amiúde perante a Suprema Corte Administrativa (BERGSTRÖM, 1979, p. 41; RODHE, 1960, p. 288), do mesmo modo que no Brasil já existe uma ampla experiência doutrinária e jurisprudencial sobre a distinção entre a elisão e a evasão tributárias (FALCÃO, 1971, p. 73; NOGUEIRA, 1989, p. 204-205; BECKER, 1998, p. 151; DÓRIA, 1977, p. 126-128; TORRES, 2013, p. 162-163; MARINS, 2002, p. 31-32; PRATES, 1992, p. 53-54; COELHO; DERZI, 1999, p. 233-234; BALEEIRO, 1974, p. 166; CAMARGO, 2008, p. 50-51).

No que toca ao tratamento da propriedade, como se pode ver, mesmo mantida a sua compreensão como direito subjetivo, está longe o Reino da Suécia de ser considerado um exemplo concreto do compromisso com uma visão do liberalismo econômico puro.

\section{Trabalho e atividade empresarial}

O desenvolvimento de atividade voltado a converter os objetos em bens, seja desempenhado em regime de autonomia, seja desempenhado em regime de subordinação, seja ele apto a caracterizar o que o executa como ferramenta animada, seja ele remunerado, é outro dos elementos a serem necessariamente considerados na caracterização do sistema econômico.

O artigo 17 do Capítulo 2 indica como fundamento para as restrições ao direito aos negócios ou ao exercício de uma profissão exclusivamente o interesse público, e nunca exclusivamente para o fim de atender aos interesses econômicos de um indivíduo ou empresa em particular.

Entretanto, esse direito pode ser objeto de restrições em relação a estrangeiros que estejam no território do Reino da Suécia, de acordo com o artigo 25 do mesmo Capítulo 2, embora tal cláusula tenha de ser interpretada em consonância com a interdição à discriminação étnica ou de origem, isto é, à discriminação arbitrária (NYMAN, 1982, p. 193; GALLO, 1992, p. 304-305). 
Nas décadas de 1960 e 1970, houve um grande afluxo de imigrantes provenientes do Terceiro Mundo buscando refúgio e asilo (KNUDSEN, 1997, p. 227), e esse tem sido um dos principais motivos de polêmica em termos não somente da política relacionada ao trabalho, mas também de acesso aos serviços públicos.

Contrariando a concepção própria de um liberalismo aos moldes clássicos, o artigo 14 do Capítulo 2 do Instrumento de Governo reconhece a possibilidade de os sindicatos, negociando com um empregador ou associação de empregadores, estabelecerem os termos das relações de trabalho, salvo a existência de lei em sentido contrário.

É de se notar, outrossim, a atribuição expressa, no artigo $2^{\circ}$ do Capítulo 1 do Instrumento de Governo do Poder Público, de assegurar o direito ao trabalho, entrando em choque com a concepção puramente liberal, que reduz a oferta ao trabalhador a uma simples manifestação de vontade do empregador, que teria liberdade para admitir ou não o indivíduo.

O modelo sueco de relações do trabalho repousa sobre um sistema centralizado e caracterizado por políticas orçamentárias e ativas de emprego (JØRGENSEN, 2003, p. 129) baseadas em dois pilares, que seriam uma forte incitação à produção individual de riquezas e o estabelecimento de um relativamente mitigado nível de desigualdade nas remunerações (SCHMIDT, 1977, p. 247; TOUZÉ, 2007, p. 42; UNION EUROPÉENE, 2016).

Isso não é de surpreender, já que a Suécia é considerada o arquétipo do Estado-Providência, onde este regime político-econômico se teria realizado com a maior amplitude (ELLINGSAETER, 1998, p. 60), enfatizando-se que o movimento sindical, ali, sempre apoiou o Estado-Providência e a extensão dos serviços sociais, e a respectiva plataforma fora encampada pelos partidos de orientação social-democrata (JØRGENSEN, 2003, p. 130; BURDEAU, 1956, p. 123), algo que chama a atenção, uma vez que, no seio da esquerda, como observou um dos mais acatados analistas, são frequentes "páginas sempre mais polêmicas e sempre mais documentadas sobre a crise deste Estado capitalista mascarado que é o Estado de bem-estar, sobre a hipócrita integração que levou o movimento operário à grande máquina do Estado das multinacionais." (BOBBIO, 2006, p. 133).

Costuma-se apontar no Reino da Suécia, ainda, a abertura do mercado profissional para as mulheres, com jornada de trabalho mais reduzida que os homens (ELGÀN, 2009, p. 86), e considera-se, ali, presente uma das mais expressivas taxas de participação feminina no mercado de trabalho.

De outra parte, registre-se que ali o poder de o empregador unilateralmente dar por extinta a relação de trabalho sofre fortíssimas restrições, diferentemente do que ocorre no Brasil, a começar pela taxatividade das hipóteses em que se admite o trabalho temporário (SIGEMAN, 2002, p. 260).

Como se pode ver, o Reino da Suécia não se converteu em um Estado economicamente "subdesenvolvido" pelo simples fato de se reconhecer, de direito e de fato, força ao movimento sindical e dar aos denominados "encargos sociais" o caráter de "direitos subjetivos" do trabalhador, como pressuposto, inclusive, da possibilidade real de fruição por parte deste dos direitos individuais típicos do Estado liberal (TRINDADE, 1995, p. 33; SILVA, 2013, p. 289). 
E mesmo quando se procurou realizar uma revisão, no sentido de uma liberalização maior da economia, não se chegou a retornar aos tempos em que se considerava a formação dos sindicatos um verdadeiro delito de coalizão.

O tratamento da atividade empresarial, outrossim, incorpora o conceito econômico de "ramos de atividade" para efeitos tributários, dando como tais aquelas partes da atividade explorada por uma empresa que se possam autonomizar (ALHAGER, 2003, p. 11-12).

Interessante observar que, usualmente, quando a atividade empresarial seja explorada por pessoa jurídica, esta adote a forma ou de sociedade por ações, ou de sociedade em nome coletivo, ou de cooperativa, diversamente do que ocorre no Brasil, que desde 1919 incorporou a inovação alemã das sociedades por quotas de responsabilidade limitada, que passou a ser a forma societária preferencial neste último país (GONÇALVES NETO, 2010, p. 315; ASCARELLI, 1969, p. 151; RIZZARDO, 2013, p. 1130; REQUIÃO, 1981, p. 342).

Mesmo baseada a economia sueca na concentração empresarial, a Lei Concorrencial de 1970 atribui ao Ombudsman da Concorrência, que atua perante o Tribunal de Mercados, a competência para o controle das práticas restritivas que possam afetar a formação dos preços, inibir a produtividade na indústria e comércio, inibir ou dificultar o ingresso de concorrentes no mercado, ou, de alguma forma, repercutir em interesse público definido (BOHLIN, 1987, p. 31).

A grande multiplicidade de sociedades anônimas, outrossim, também pode explicar o dado de o capitalismo sueco estar bem longe do modelo ideal da "livre concorrência" presente nos grandes teóricos dos primórdios do liberalismo econômico, radicando, antes, na concentração empresarial (SÁNCHEZ DE DIOS, 1993, p. 293-294), notadamente no âmbito da ligação entre várias fases da produção e da distribuição do bem, sob o comando da mesma empresa - a chamada "concentração vertical" -, bem como das convenções voltadas, nos limites da lei, a configurar a estrutura de mercado e a fortalecer a musculatura financeira dos respectivos agentes (STRÖMHOLM, 1971, p. 224-225).

Quanto ao regime do segredo industrial e comercial, para que a informação se submeta a ele, é necessário, na Suécia, que se ligue à atividade econômica específica desempenhada pelo respectivo beneficiário, que sua revelação seja apta a provocar para este um prejuízo em face da concorrência, e que não seja acessível a qualquer pessoa salvo mediante pronunciamento do respectivo detentor (VINKA, 1999, 2000, p. 34-35). A valorização de tal segredo em muito decorreria dos investimentos em longo prazo no desenvolvimento tecnológico e do incremento das técnicas mais sofisticadas e caras de marketing, influenciando, outrossim, a busca de soluções de conflitos de interesse fora da publicidade dos processos judiciais (STRÖMHOLM, 1971, p. 225).

Os regimes do "trabalho" e da "atividade empresarial" na Suécia, como se pode notar pelos exemplos trazidos, sem que se descaracterize o regime capitalista, não se constituem em manifestações do Estado Mínimo almejado pelos adversários do Welfare State, nem se chegou a tanto, mesmo quando do movimento de liberalização verificado no início da década de 1990. 


\section{Atuação do Estado sobre o domínio econômico e serviços públicos}

Considerando que já praticamente se forma uma espécie de "senso comum" em torno de ser um sintoma de "subdesenvolvimento" a autorização constitucional para que o Estado conforme, heteronomamente, as relações econômicas, talvez este tópico pareça surpreendente, uma vez que a Constituição sueca, tal qual a brasileira, contém previsão nesse sentido.

A atuação do Estado sobre a atividade econômica tem a sua disciplina geral no artigo $2^{\circ}$ do Capítulo 8, que reserva à lei não somente o tratamento do status das pessoas, mas também as suas mútuas relações econômicas, quando sejam de indivíduo a indivíduo (item 1); as relações dos indivíduos com as instituições públicas, bem como a própria autorização para estas atuarem, também ficam sob a reserva de lei (item 2).

Abrem-se, no que se refere à política econômica passível de ser adotada no Reino da Suécia, espaços tanto para a caracterizada pelo atendimento de objetivos ativos quanto para a caracterizada pelo atendimento de objetivos restritivos, recordando a distinção posta no âmbito doutrinário por eminente Professor da Faculdade de Direito do Largo São Francisco:

Os ativos correspondem a um novo padrão de desempenho que se pretende introduzir ou desenvolver no sistema econômico. Assim, o desenvolvimento, a distribuição de renda, a industrialização constituem exemplos de objetivos deste tipo. Normalmente, eles impulsionam o sistema para novas posições ou para novos padrões de desempenho. Os segundos, pelo contrário, referem-se à manutenção de determinadas posições de equilíbrio que não pode ser rompido, sob pena de se destruírem as condições básicas para o próprio funcionamento harmonioso do sistema. (NUSDEO, 2015, p. 149).

Por sinal, é exatamente a admissão de uma política econômica pública à volta de objetivos "ativos" que veio, a partir da década de 1930, a preparar o terreno para a ideia de um orçamento voltado a assegurar recursos ao Poder Público para dinamizar a economia nacional (STJERNQUIST, 1962, p. 225-256).

É de se notar que, na Escandinávia como um todo, a noção de Direito Econômico não teve uma discussão muito aprofundada, presente uma preferência pela noção de "Direito dos Mercados" (BERNITZ, 1979, p. 74) aparentada, em muito, à tese que considera como objeto do Direito Econômico a "organização dos mercados" (VIDIGAL, 1977, p. 44), mais restritiva que aquela que o toma como incidindo sobre a política econômica como um todo (SOUZA, 1980, p. 14; CAMARGO, 2014, p. 22-23), embora algo mais abrangente do que aquela que o toma como voltado estritamente à atuação do Estado sobre e no domínio econômico (VENÂNCIO FILHO, 1998, p. 77), recordando, ainda, que as expressões "atuação do Estado sobre o domínio econômico" e "atuação do Estado no domínio econômico" buscam substituir as dificuldades geradas pelas expressões "intervenção indireta do Estado no domínio econômico" e "intervenção direta do Estado no domínio econômico" (GRAU, 2007, p. 148). 
A base para a industrialização sueca criou-se e foi construída socialmente a partir dos anos 1930, tendo ela conseguido manter-se neutra durante a II Guerra Mundial (KNUDSEN, 1997, p. 226), máxime porque os seus principais parceiros comerciais eram inimigos entre si - Alemanha e Grã-Bretanha (LA RUCHE, 1953, p. 122) -, embora valha notar que, nesse período, o Governo de coalizão, que incluía todos os partidos políticos, exceto os comunistas, chegou a adotar uma política econômica de tendências filogermânicas, especialmente no que se refere aos sindicatos (APPELQVIST, 2008, p. 74).

Seu processo de industrialização, mais ágil que o dos demais países da região, conduziu a que se tornasse o líder industrial na Escandinávia (ELLINGSAETER, 1998, p. 61), deixando a situação de "país pobre" que ostentava até 1870 (SANANDAJI, 2012, p. 10), ano em que a Revolução Industrial começou a influenciar mais decisivamente a respectiva economia (STRÖMHOLM, 1971, p. 224-225).

Os que atribuem a essa data a condição de marco a partir do qual a Suécia teria acelerado o processo de industrialização em razão de uma liberação dos contratos e um reforço do direito de propriedade que se teria retardado a partir do início da década de 1930, em virtude do intervencionismo (SANANDAJI, 2012, p. 10), é de ser-lhes lembrado que o regime contratual permaneceu ali sem alterações de monta de 1734 até 1915 (WALIN, 1956, p. 394), e que na década de 1980, uma proposta de Código Civil, parcialmente inspirada no Código Napoleão, não conseguiu lograr aprovação no Parlamento por ser julgada "excessivamente avançada" (BERNITZ, 2007b, p. 20).

Ainda, muito do que enaltecem alguns como a paulatina substituição da coerção estatal pela responsabilidade livremente assumida, o sistema privado de legislação conhecido como lex mercatoria (CAMARGO, 2005, p. 315) acaba tendo a liberdade na discussão das respectivas cláusulas mitigada em razão de cláusulas que, naquele País, são predeterminadas, padronizadas pelas organizações empresariais (BERNITZ, 2013, p. 41-2), tema que se colocou amiúde no Brasil ao se debater doutrinariamente a questão dos contratos de adesão (SOUZA, 2002a, p. 153-154; GRAU; FORGIONI, 2005, p. 36-37; ALMEIDA, 2009, p. 170-171; BESSONE, 1987, p. 76-77; RIZZARDO, 2013, p. 92-94; BULGARELLI, 1997, p. 195-196; NADER, 2013, p. 48-49; GOMES, 2009, p. 128-129; CHAVES, 1984, p. 378-380; SILVA, 1976, p. 25-26; MARIANI, 2007, p. 73; BEVILAQUA, 1979, p. 195; PEREIRA, 1993, p. 50-51) e que esteve por detrás da construção da orientação consolidada no verbete 176 da Súmula da Jurisprudência predominante no Superior Tribunal de Justiça.

O desenho dos serviços públicos, no artigo $2^{\circ}$ do Capítulo 1 , em linha de princípio, tem o referencial liberal da liberdade e da igualdade de todos os indivíduos entre si e da dignidade que cada qual ostenta, e a visão a seu respeito em muito se aproxima da compreensão do "princípio da subsidiariedade"3 (BOHLIN, 1987, p. 34).

3 Aplicável, a bem de ver, muito mais à atividade econômica, de acordo com a doutrina majoritária. 
Entretanto, ingressa, ao se definirem os fins a que eles se voltam, o dado do Estado Social, já que se referem ao bem-estar pessoal, econômico e cultural de cada indivíduo, algo totalmente distinto do modelo de Estado liberal puro, voltado à salvaguarda somente dos direitos civis e políticos, com o foco nos titulares do poder econômico privado (BONAVIDES, 2001, p. 69).

Comparece, também ali, como dever do Estado, assegurar o direito à habitação, a promoção da assistência e da previdência social, bem como as condições de boa saúde, o que contradiz, a bem de ver, a percepção da ausência de menções a "direitos sociais" (SÁNCHEZ DE DIOS, 1993, p. 288), embora se encontrasse, na doutrina, a possibilidade de identificar a não vinculação jurídica a partir delas (NYMAN, 1982, p. 178), em contradição com a visão inerente ao Estado Social.

O desenvolvimento dessas prestações de caráter universal é tido como um elemento fundamental de construção da comunidade nacional e da sociedade democrática naquele País (BURDEAU, 1957, p. 101), e a partir de uma filosofia voltada à redução das desigualdades, passou-se a estruturar um sistema de acesso universal a prestações que assegurassem a cada indivíduo a sobrevivência, a despeito das oscilações do mercado de trabalho (AUCANTE, 2009, p. 71), prestações, estas que abrangeriam tanto as categorias que estivessem atendidas por convenções coletivas, que ofertam as bases para o cálculo dos benefícios, quanto às que não fossem por estas atingidas, que teriam calculados os benefícios a partir do que perceberiam as profissões que pudessem ser a elas comparáveis (CHRISTENSEN, 1980, p. 168).

A política habitacional, ali, tem oscilado entre as medidas legisladas, normalmente postas para limitar o valor dos locativos, e as medidas decorrentes de negociação coletiva entre associações de locadores e de locatários, desde a terceira década do século XX (VICTORIN, 1979, p. 236-238).

É de se notar, entretanto, que quando da difusão do denominado "novo modelo de gestão pública", voltado à implementação de técnicas gerenciais mais próximas do setor privado (MOREIRA NETO, 2001, p. 125-126), a mais fervorosa, na Escandinávia, adesista a ele foi, sem sombra de dúvidas, a Suécia (OLSEN, 2007, p. 387), sendo de notar que a própria noção da "responsabilidade política", neste campo, seria substituída pela noção de "responsabilidade gerencial", com a introdução, em larga escala, da eficiência dos resultados, ao lado do procedimento e da legalidade, entre os dados de legitimidade da ação do Poder Público (MATTEI, 2007, p. 408).

O encorajamento à adoção desse novo modelo em muito se deveu à inflação que se abateu sobre o País a partir da segunda metade de 1989 (CHARDIN, 1991, p. 27), com o que veio a ganhar especial alento o discurso voltado a centrar a política econômica pública basicamente na manutenção do poder aquisitivo da moeda e na busca incessante pelo equilíbrio orçamentário (TORRES, 2013, p. 124; KRUGMAN, 2014, p. 50).

Destaque-se que, em setores alcançados pela privatização no período entre 1990 e 2004, quando se verificou o engajamento maior no movimento de "redução do Estado", não se verificou, no âmbito privado, uma expansão proporcional, e o "enxugamento" da máquina pública nesses se- 
tores, bem como da assistência à velhice, acaba por desaguar nos problemas decorrentes do aumento das doenças e do envelhecimento da população (ANKARLOO, 2009).

Em certo sentido, a responsabilidade a partir dos objetivos e dos resultados obtidos, pelo modelo que se quis implementar também em países mais resistentes a ele, acaba acoplando-se ao problema da adequação dos meios buscados aos fins perseguidos e à própria previsibilidade destes últimos a partir do cálculo (CHRISTENSEN; FIRMREITE; LÆGREID, 2007, p. 434).

De outra parte, a paulatina sujeição, a partir do início da década de 1990, das mulheres à mesma jornada de trabalho dos homens mais reforçou a necessidade de se manterem, como estruturas públicas, creches e escolas maternais (ELGÀN, 2009, p. 85-6; SÁNCHEZ DE DIOS, 2004, p. 112).

A retração da atividade econômica, identificada a partir de 2008 com a crise deflagrada nos EUA, em virtude da dependência da economia sueca em relação às exportações, veio a refletir no aumento da taxa de desemprego e, ipso facto, na própria configuração do seguro-desemprego (COULET, 2009), sendo de notar que a tentativa de alijar da gestão deste os sindicatos ocorrida no início da década de 1990, foi revertida com a eleição dos social-democratas em 1994 (SÁNCHEZ DE DIOS, 2004, p. 113).

Mesmo a implementação do "novo modelo de gestão pública" esteve muito longe de traduzir-se como adoção do "Estado Mínimo" que tem sido preconizado como panaceia para os problemas inerentes ao Terceiro Mundo, até porque, para que um tal modelo se pudesse realizar à plena, ter-se-iam de amoldar os objetivos da atividade estatal aos da atividade econômica privada, isto é, converter a busca do interesse daquele que tem o comando da atividade em meio involuntário de promoção do interesse geral, ao invés de a procura deste último ser o objetivo de toda a construção da máquina de coação.

\section{Conclusão}

Os dados trazidos a exame acerca da experiência de Constituição Econômica na Suécia revelam um ordenamento que, mesmo nos períodos com predominância de orientação avessa à atuação do Estado sobre e no domínio econômico, não se implementaram as teses do "Estado Mínimo", voltado a assegurar tão somente a propriedade privada em sua plenitude e a liberdade de contratar, muito menos a da substituição do Direito estatal pela lex mercatoria.

Nota-se, ainda, que muitos dos problemas acerca dos quais a doutrina se debate no Terceiro Mundo, como é o caso da rejeição aos tributos, da existência de populações autóctones com um modus vivendi distinto daquele da civilização "cristã-ocidental" e suas relações com a economia nacional, a relação dos trabalhadores e do empresariado com o Estado-Providência, a medida da realizabilidade dos direitos que não se enquadrem nos parâmetros estritos do liberalismo também se põem para a doutrina na Suécia, embora trabalhando com um contexto de menor desigualdade social. 
A despeito de, doutrinariamente, não se haver desenvolvido uma "Escola Sueca de Direito Econômico", ou mesmo uma doutrina voltada especificamente ao desenvolvimento desse ramo do Direito, o pensamento jurídico daquele País tem se debruçado sobre os aspectos jurídicos da respectiva política econômica em termos que em muito se aproximam do debate travado no Brasil e em outras partes do mundo ocidental onde a disciplina logrou um efetivo avanço na sistematização.

\section{Referências}

ALHAGER, Eleonor. Restructure of companies in Swedish Income Tax Law - what is a branch of activity? Scandinavian Studies in Law. Stockholm, v. 44, p. 11-9, 2003.

ALMEIDA, João Baptista de. A proteção jurídica do consumidor. São Paulo: Saraiva, 2009.

ANDERSSON, Edward. How Swedish Tax Law affected Finnish Income and Net Wealth Taxation. Scandinavian Studies in Law, Stockholm, v. 30, p. 11-28, 1986.

ANKARLOO, Daniel. The Swedish welfare model - counter-arguments for neoliberal myths and assertions. 2009. Disponível em: <http://www.mah.se/PageFiles/98343/Microsoft\%20Word\%20-\%20the\%20 swedish\%20welfare\%20modelneolib.pdf>. Acesso em: 22 fev. 2016.

APPELOVIST, Örjan. Deux voies politiques vers le plein-emploi et deux modèles sociaux: France-Suède. La Revue de l'IRES, Paris, v. 56, n. 1, p. 56-93, janv./mars. 2008.

ASCARELLI, Tullio. Problemas das sociedades anônimas e direito comparado. São Paulo: Saraiva, 1969.

AUCANTE, Yohann. Les défis de l'universalité: le gouvernment local de la protection sociale en Suède et Norvège. Critique Internationale, Paris, v. 43, n. 2, p. 69-86, 2009. Disponível em: <https:// www.cairn.info/revue-critique-internationale-2009-2-page-69.htm >. Acesso em: 22 out. 2015.

ÁVILA Humberto Bergmann. Sistema constitucional tributário. São Paulo: Saraiva, 2012.

ÁVILA, Humberto Bergmann. Teoria da igualdade tributária. São Paulo: Malheiros, 2009.

BALEEIRO, Aliomar de Andrade. Uma introdução à ciência das finanças. Rio de Janeiro: Forense, 1974.

BASSE, Ellen Margarethe. Environmental liability - modern developments. Scandinavian Studies in Law, Stockholm, v. 41, p. 31-54, 2001.

BEAUMONT-VASSY, Édouard Ferdinand de la Moumière, vicomte de. Les suédois depuis Charles XII. Paris: Librairie de Charles Gosselin, 1841. v. 2.

BECKER, Alfredo Augusto. Teoria geral do Direito Tributário. São Paulo: Lejus, 1998.

BERGSTRÖM, Sture. Private Law and Tax Law. Scandinavian Studies in Law, Stockholm, v. 23, p. 31-51, 1979.

BERNITZ, Ulf. Commercial norms and Soft Law. Scandinavian Studies in Law, Stockholm, v. 58, p. 29-43, 2013. 
BERNITZ, Ulf. Market Law as a legal discipline. Scandinavian Studies in Law, Stockholm, v. 23, p. 53-76, 1979.

BERNITZ, Ulf. The European Constitutional Project and the Swedish Constitution. Scandinavian Studies in Law, Stockholm, v. 52, p. 49-64, 2007a.

BERNITZ, Ulf. What is Scandinavian Law? Scandinavian Studies in Law, Stockholm, v. 50, p. 13-30, $2007 b$.

BESSONE, Darcy. Do contrato - teoria geral. Rio de Janeiro: Forense, 1987.

BEVILAQUA. Clovis. Código Civil dos Estados Unidos do Brasil comentado. Rio de Janeiro: Rio, 1979. v. 2.

BOBBIO, Norberto. O futuro da democracia. Tradução Marco Aurélio Nogueira. Rio de Janeiro: Paz e Terra, 2006.

BOHLIN, Alf. The office of the Competition Ombudsman and the local authorities. A collision between Local Government Law and Business Law. Scandinavian Studies in Law, Stockholm, v. 31, p. 29-39, 1987.

BONAVIDES, Paulo. Do país constitucional ao país neocolonial. São Paulo: Malheiros, 2001.

BORGES, José Souto Maior. IPTU: progressividade. Revista de Direito Tributário, São Paulo, v. 16, n. 59, p. 73-94, jan./mar. 1992.

BRITTO, Hegel Pereira. Direito à propriedade e ameaças à soberania: consequências. 2010. Trabalho de Conclusão de Curso (Graduação)-Faculdade de Direito da Universidade Federal do Rio Grande do Sul, Porto Alegre, 2010.

BULGARELLI, Waldirio. Contratos mercantis. São Paulo: Atlas, 1997.

BURDEAU, Georges. Traité de Science Politique. Paris: Librairie Generale de Droit et Jurisprudence, 1953. t. 5 .

BURDEAU, Georges. Traité de Science Politique. Paris: Librairie Generale de Droit et Jurisprudence, 1956. t. 6.

BURDEAU, Georges. Traité de Science Politique. Paris: Librairie Generale de Droit et Jurisprudence, 1957. t. 7.

CAMARGO, Ricardo Antonio Lucas. Curso elementar de Direito Econômico. Porto Alegre: Nuria Fabris, 2014.

CAMARGO, Ricardo Antonio Lucas. ICMS e equilíbrio federativo na Constituição Econômica. Porto Alegre: Sergio Antonio Fabris, 2008.

CAMARGO, Ricardo Antonio Lucas. Lex mercatoria, exclusão social e direitos humanos. In: LEÃO, Renato Zerbini Carneiro et al. Os rumos do Direito Internacional dos Direitos Humanos - ensaios em homenagem ao Professor Antônio Augusto Cançado Trindade. Porto Alegre: Sergio Antonio Fabris, 2005. t. 3, p. 313-328. 
CARRAZZA, Roque Antonio. Curso de Direito Constitucional Tributário. São Paulo: Malheiros, 2011.

CHARDIN, Christian. Conjoncture de l'économie suédoise: retour à la stagflation. Chronique d'actualité de la S.É.D.É.I.S., Paris, v. 40, n. 1, p. 25-32, 15 janv. 1991.

CHAVES, Antonio. Tratado de Direito Civil. São Paulo: Revista dos Tribunais, 1984. v. 2, t. 1.

CHRISTENSEN, Anna. Disqualification from unemployment benefits: a critical study in Swedish Social Security Law. Scandinavian Studies in Law, Stockholm, v. 24, p. 153-174, 1980.

CHRISTENSEN, Tom; FIRMREITE, Anne Liese; LÆGREID, Per. La réforme des administrations de l'emploi et de la protection sociale. Revue Internationale des Sciences Administratives, Paris, v. 73, n. 3, p. 429-450, juil./sept. 2007.

COELHO, Sacha Calmon Navarro; DERZI, Misabel de Abreu Machado. Direito Tributário atual. Rio de Janeiro: Forense, 1999.

COULET, Cyril. Suède. Controverses autour du système d'assurance chômage. Grande Europe. Paris, n. 9, juin. 2009. Disponível em: <http://www.ladocumentationfrancaise.fr/pages-europe/ d000448-suede.-controverses-autour-du-systeme-d-assurance-chomage-par-cyril-coulet $>$. Acesso em: 25 fev. 2016.

DIFINI, Luiz Felipe Silveira. Proibição de tributo com efeito de confisco. Porto Alegre: Livraria do Advogado, 2007.

DÓRIA, Antonio Roberto Sampaio. Elisão e evasão fiscal. São Paulo: José Bushatsky, 1977.

ELGÀN, Elisabeth. Pouvoir économique en Suède et inegalité des sexes. Informations Sociales, Paris, v. 64, n. 151, p. 84-91, 2009. Disponível em: <http://www.cairn.info/revue-informations-sociales-2009-1-page-84.htm>. Acesso em: 25 fev. 2016.

ELLINGSAETER, Anne Lise. Dual breadwinner societies: provider models in the Scandinavian welfare states. Acta Sociologica, Turku, v. 41, n. 1, p. 59-73, 1998.

FALCÃO, Amílcar de Araújo. O fato gerador da obrigação tributária. São Paulo: Revista dos Tribunais, 1971.

FERREIRA, Amaro Luiz. A garantia da função social da propriedade mineral na evolução do Direito Minerário brasileiro. 2012. Trabalho de Conclusão de Curso (Graduação)-Faculdade de Direito da Universidade do Estado do Amazonas, Manaus, 2012.

GALLO, Carlos Alberto Provenzano. $\bigcirc$ "Ombudsman" sueco contra a discriminação étnica e imigratória. Cadernos de Direito Constitucional e Ciência Política, São Paulo, v. 1, n. 1, p. 303-307, out./ dez. 1992.

GOMES, Orlando. Contratos. Rio de Janeiro: Forense, 2009.

GONÇALVES NETO, Alfredo de Assis. Direito de Empresa. São Paulo: Revista dos Tribunais, 2010. 
GONÇALVES, Rosaura Pereira. Mineração em terras indígenas. 2015. Trabalho de Conclusão de Curso (Graduação)-Faculdade de Direito da Universidade Federal do Rio Grande do Sul, Porto Alegre, 2015.

GRAU, Eros Roberto. A ordem econômica na Constituição de 1988 (interpretação e crítica). São Paulo: Malheiros, 2007.

GRAU, Eros Roberto; FORGIONI, Paula Andréa. O Estado, a empresa e o contrato. São Paulo: Malheiros, 2005.

HAMMARSKIÖLD, Peder; JANSSON, Daniel; GRÜBBSTRÖM, Ulf. Sweden. In: BRENNEN, Allen (Org.). The Comparative Law Yearbook of International Business - security over immovable in selected jurisdictions. Salzburg, 2005. p. 425-451.

HECKSCHER, Eli R. La época mercantilista. Tradução Wenceslao Roces. México: Fondo de Cultura Económica, 1983.

HORTA, Raul Machado. Direito Constitucional. Belo Horizonte: Del Rey, 2010.

INSTITUT SUÉDOIS. Le peuple sami en Suède: un peuple arctique aux racines ancestrales. 2011. Disponível em: <http://www.swedenabroad.com/ImageVaultFiles/id_17422/cf_2/Le-peuple-Sami-en-Suede.PDF>. Acesso em: 20 fev. 2016.

JØRGENSEN, Henning. Le rôle des syndicats dans les réformes sociales en Scandinavie dans les années quatre-vingt-dix. Revue Française des Affaires Sociales, Paris, v. 4, n. 4, p. 121-150, oct./déc. 2003.

KELSEN, Hans. Teoria pura do Direito. Tradução João Baptista Machado. Coimbra: Arménio Amado, 1974.

KNUDSEN, Knud. Scandinavian neighbours with different character? Attitudes toward immigrants and national identity in Norway and Sweden. Acta Sociologica, Turku, v. 40, i. 3, p. 223-243, 1997.

KRUGMAN, Paul. A Suécia cai na armadilha. Carta Capital, São Paulo, v. 20, n. 798, p. 50, maio 2014.

LA RUCHE, Francis. La neutralité de la Suède. Paris: Nouvelles Éditions Latines, 1953.

LAPEYRE, Yann. Les aspects juridiques de la reconnaissance et de la protection du peuple autochtone Same en Scandinavie: avancées consequentes et lacunes recurrentes de la prise en compte récente des interêts et de l'identité d'un groupe minoritaire longtemps assimilé. 2007. Disponível em: <http:// leuropedeslibertes.u-strasbg.fr/article.php?.id_article $=389 \&$ \&id_rubrique $=72>$. Acesso em: 20 fev. 2016.

LEAL JÚNIOR, Cândido Alfredo da Silva. Tratamento judicial de conflitos entre grupos indígenas e agentes públicos: estudo de caso. Revista do CEJ, Brasília, DF, v. 16, n. 57, p. 103-7, maio/ago. 2012.

MARIANI, Irineu. Contratos empresariais. Porto Alegre: Livraria do Advogado, 2007.

MARINS, James. Elisão tributária e sua regulação. São Paulo: Dialética, 2002. 
MATA-MACHADO, Edgar de Godói da. Elementos de teoria geral do Direito. Belo Horizonte: Vega, 1972.

MATTEI, Paola. La responsabilité politique et managériale: un écart qui se creuse dans l'organisation de l'aide sociale. Revue Internationale des Sciences Administratives, Paris, v. 73, n. 3, p. 403-428, juil./sept. 2007.

MAXIMILIANO, Carlos. Hermenêutica e aplicação do Direito. Rio de Janeiro: Forense, 2002.

MOLL, Luíza Helena. Externalidades e apropriação: projeções sobre o Direito Econômico na nova ordem mundial. In: CAMARGO, Ricardo Antonio Lucas (Org.). Desenvolvimento econômico e intervenção do Estado na ordem constitucional - estudos jurídicos em homenagem ao Professor Washington Peluso Albino de Souza. Porto Alegre: Sergio Antonio Fabris, 1995. p. 139-160.

MONTEIRO, Marcela Nogueira. O caso Raposa Serra do Sol e a jurisprudência do Tribunal Regional Federal da Primeira Região: uma análise do contexto jurisprudencial no qual se inserem as 19 condicionantes. Monografia (Especialização)-Sociedade Brasileira de Direito Público, São Paulo, 2010.

MOREIRA NETO, Diogo de Figueiredo. Administração pública gerencial. A \& C - Revista de Direito Administrativo e Constitucional, Curitiba, v. 1, n. 2, p. 119-129, 2001.

MOREIRA, Vital. Economia e Constituição - para o conceito de Constituição Econômica. Coimbra: Faculdade de Direito da Universidade de Coimbra, 1974.

MUSSET, Louis. Les peuples scandinaves au Moyen Âge. Paris: Presses Universitaires de France, 1951.

NABONNE, Bernard. Bernadotte. Tradução Jefferson de Lemos. Rio de Janeiro: Emiel, 1940.

NADER, Paulo. Curso de Direito Civil. Rio de Janeiro: Forense, 2013. v. 3.

NEUMANN, Robert G. European and comparative government. New York: McGraw-Hill, 1960.

NOGUEIRA, Ruy Barbosa. Curso de Direito Tributário. São Paulo: Saraiva, 1989.

NUSDEO, Fábio. Curso de Economia Política - introdução ao Direito Econômico. São Paulo: Revista dos Tribunais, 2015.

NYMAN, Olle. The new Swedish Constitution. Scandinavian Studies in Law, Stockholm, v. 26, p. 170-199, 1982.

OLIVECRONA, Karl. The legal theories of Axel Hägström and Vilhelm Lundstedt. Scandinavian Studies in Law, Stockholm, v. 3, p. 125-150, 1959.

OLSEN, Silvia. La fragmentation et la coordination dans le secteur ferroviaire scandinave. Revue de Sciences Administratives, Paris, v. 73, n. 3, p. 385-401, juil./sept. 2007.

PEREIRA, Caio Mário da Silva. Instituições de Direito Civil. Rio de Janeiro: Forense, 1993. v. 3.

PERLINGEIRO, Ricardo. A justiça administrativa brasileira comparada. Revista do CEJ, Brasília, v. 16, n. 57, p. 6-18, maio/ago. 2012. 
PLAUEN, Frédérique von. L' allemansrätt ou une concéption particulière du droit de propriété en Droit Suédois. Revue Internationale de Droit Comparé, Paris, v. 57, n. 4, p. 921-941, août/déc. 2005.

PORCIONATO, Ana Lúcia; LOBO, Artur Mendes. A vez do seguro ambiental: aspectos internacionais e as inovações da Lei Complementar n. 126, de 16.01.2007. Revista IOB de Direito Civil e Processual Civil, São Paulo, v. 9, n. 49, p. 46-91, set./out. 2007.

PRATES, Renato Martins. Interpretação tributária e a questão da evasão fiscal. Belo Horizonte: Del Rey, 1992.

REQUIÃO, Rubens. Curso de Direito Comercial. São Paulo: Saraiva, 1981. v. 1.

RIZZARDO, Arnaldo. Contratos. Rio de Janeiro: Gen/Forense, 2013.

RODHE, Knut. La surveillance des sociétés par actions dans le Droit suédois. Revue Trimestrielle de Droit Commercial, Paris, v. 12, n. 2, p. 283-9, avril/juin. 1960.

SAMPAIO, Francisco José Marques. O dano ambiental e a responsabilidade. Revista de Direito Administrativo, Rio de Janeiro, v. 45, n. 185, p. 41-62, jul./set. 1991.

SANANDAJI, Nima. The surprising ingredients of Swedish success - free market and social cohesion. London: Institut of Economic Affairs, 2012.

SÁNCHEZ DE DIOS, Manuel. El modelo sueco del Estado de Bienestar. Revista de Estudios Políticos, Madrid, n. 79, p. 283-303, enero/marzo 1993.

SÁNCHEZ DE DIOS, Manuel. Estudio comparado de path dependence del Estado de Bienestar en los casos de USA, Suecia y España. Revista de Estudios Políticos, Madrid, v. 124, p. 95-128, abr./jun. 2004.

SANTANA, Heron José de. Justiça fiscal e extrafiscal nos tributos ambientais. Revista do Programa de Pós-Graduação da UFBA, Salvador, n. 11, p. 37-56, jan./dez. 2004.

SANTILLI, Juliana. Aspectos jurídicos da mineração e do garimpo em terras indígenas. In: SANTILLI, Juliana et al. Os direitos indígenas e a Constituição. Porto Alegre: Sergio Antonio Fabris, 1993.

SCHMIDT, Folke. From socialism to labourism. Scandinavian Studies in Law, Stockholm, v. 21, p. 241-256, 1977.

SIGEMAN, Tore. Employment protection in Scandinavian Law. Scandinavian Studies in Law, Stockholm, v. 48, p. 257-275, 2002.

SILVA, Clovis Veríssimo do Couto e. A obrigação como processo. São Paulo: José Bushatsky, 1976.

SILVA, José Afonso da. Curso de Direito Constitucional positivo. São Paulo: Malheiros, 2013.

SILVEIRA, Alípio. Hermenêutica no Direito brasileiro. São Paulo: Revista dos Tribunais, 1968. v. 1.

SKOGH, Göran. Property rights and the environment - a Law and Economics approach. Scandinavian Studies in Law, Stockholm, v. 40, p. 483-504, 2000. 
SOUZA FILHO, Carlos Frederico Marés de. O renascer dos povos indígenas para o direito. Curitiba: Juruá, 2012.

SOUZA, Washington Peluso Albino de. Direito Econômico. São Paulo: Saraiva, 1980.

SOUZA, Washington Peluso Albino de. Lições de Direito Econômico. Porto Alegre: Sergio Antonio Fabris, 2002a.

SOUZA, Washington Peluso Albino de. Teoria da Constituição Econômica. Belo Horizonte: Del Rey, $2002 b$.

STJERNQUIST, Nils. The Swedish Constitution and the budgetary principles. Scandinavian Studies in Law, Stockholm, v. 6, p. 202-228, 1962.

STRÖMBERG, Tore. Norms of competence in Scandinavian jurisprudence. Scandinavian Studies in Law, Stockholm, v. 28, p. 151-161, 1984.

STRÖMHOLM, Stig. "Public" rule making and "private": the Swedish experience. Scandinavian Studies in Law, Stockholm, v. 15, p. 219-284, 1971.

SVÅSAND, Lars; LINDSTRÖM, Ulf. Sliding towards EC membership: Norway in Scandinavian perspective. Government and Opposition, Cambridge, v. 27, i. 3, p. 330-344, summer 1992.

SWEDEN. Acts etc. Instrument of Government. 2016. Disponível em: < http://www.wipo.int/wipolex/fr/text.jsp?file_id=267691>. Acesso em: 20 jan. 2016.

SYMONIDES, Michał. Les peuples autochtones, un acteur sous-estimé: l'exemple sami. 2012. Disponível em: <http://perspectivesinternationales.com/? p=600>. Acesso em: 20 fev. 2016.

TORRES, Ricardo Lobo. Curso de Direito Financeiro e Tributário. Rio de Janeiro: Renovar, 2013.

TOUZÉ, Vincent. Les performances économiques de la Suède. Revue de l'OFCE, Paris, v. 100, n. 1, p. 31-84, janv./mars 2007.

TRINDADE, Antonio Augusto Cançado. Do Direito Econômico aos direitos econômicos, sociais e culturais. In: CAMARGO, Ricardo Antonio Lucas (Org.). Desenvolvimento econômico e intervenção do Estado na ordem constitucional - estudos jurídicos em homenagem ao Professor Washington Peluso Albino de Souza. Porto Alegre: Sergio Antonio Fabris, 1995. p. 9-38.

UNION EUROPÉENE. La politique sociale et la politique du marché du travail en Suède. Bruxelles, 1997. Disponível: <http://www.europarl.europa.eu/workingpapers/soci/w13/summary_fr.htm>. Acesso em: 20 fev. 2016.

VENÂNCIO FILHO, Alberto. A intervenção do Estado no domínio econômico. Rio de Janeiro: Renovar, 1998.

VICTORIN, Anders. Landlords and tenants in Sweden - a case of collective bargaining. Scandinavian Studies in Law, Stockholm, v. 23, p. 231-255, 1979.

VIDIGAL, Geraldo de Camargo. Teoria geral do Direito Econômico. São Paulo: Revista dos Tribunais, 1977. 
VIEIRA, Ederlandi Dutra. Proteção legal da Amazônia. 2008. Trabalho de Conclusão de Curso (Graduação)-Faculdade de Direito Metropolitana de Curitiba, São José dos Pinhais, 2008.

VINKA, Anders. Les secrets d'affaire en France et en Suède. Linköpping: Linköpping Universitet, 1999/2000. (mémoire de Maîtrise en Droit des Affaires).

WALIN, Gösta. La méthode législative dans les pays nordiques. Revue Internationale de Droit Comparé, Paris, v. 8, n. 3, p. 389-395, juil./sept. 1956.

WICKSELL, Knut. Lecciones de economía política. Tradução Francisco Sánchez Ramos. Madrid: Aguilar, 1947.

Data da submissão: 25 de agosto de 2016 Avaliado em: 01 de dezembro de 2016 (AVALIADOR A) Avaliado em: 07 de maio de 1017 (AVALIADOR B) Aceito em: 17 de julho de 2017 
